\title{
Sistema educacional e a formação de trabalhadores: a desqualificação do Ensino Médio Flexível
}

\author{
Education system and the training of workers: the disqualification \\ of flexible high school education
}

Acacia Zeneida Kuenzer (https://orcid.org/0000-0001-6429-9345) ${ }^{1}$

${ }^{1}$ Universidade Federal do Paraná. R. XV de Novembro 1299, Centro. 80060000 Curitiba PR Brasil. acaciak4@gmail.com

\begin{abstract}
This article analyzes high school education reform and its impact on the education project on those who work for a living. By analyzing Law 13.415/2017, recent statistics and the new proposal for curricular organization, arguments will be identified that point to the flexibilization of high school education as an expression of the pedagogical project of the flexible accumulation system, whose logic continues to be the unequal distribution of knowledge, but in a differentiated way. The aim is the formation of flexible subjectivities submitted to the precarity of work, naturalizing instability, insecurity and deregulation for an alleged autonomy of choice. From the ontological viewpoint, the article shows that the high school education reform responds to the alignment of the flexible accumulation system formation. In epistemological terms, it compares the conception of praxis that guided the drafting of the curricular guidelines in 2012 with the dimensions of individualism, fragmentation, presentism and pragmatism present in the new guidelines. Based on the analysis, the author emphasizes the need to create other forms of curricular organization in the exercise of autonomy by the school as an alternative for the integral formation of young individuals.

Key words High school education reform, Flexibilization of high school education, Pedagogy in the flexible accumulation system
\end{abstract}

Resumo Este artigo propõe-se a analisar a reforma do Ensino Médio e seus impactos para o projeto de educação dos que vivem do trabalho. A partir da análise da Lei 13.415/2017, das estatísticas recentes e da nova proposta de organização curricular, vai levantar argumentos que apontam a flexibilização do Ensino Médio como uma das expressões do projeto pedagógico do regime de acumulação flexivel, cuja lógica continua sendo a distribuição desigual do conhecimento, porém com uma forma diferenciada. Seu objetivo é a formação de subjetividades flexíveis que se submetam à precarização do trabalho, naturalizando a instabilidade, a insegurança e a desregulamentação em nome da suposta autonomia de escolha. Do ponto de vista ontológico, o artigo aponta que a reforma do Ensino Médio responde ao alinhamento da formação ao regime de acumulação flexivel. Do ponto de vista epistemológico, confronta a concepção de práxis que orientou a elaboração das diretrizes curriculares em 2012, com as dimensões de individualismo, fragmentação, presentismo e pragmatismo presentes nas novas diretrizes. A partir da análise, a autora reforça a necessidade de criar outras formas de organização curricular no exercício da autonomia pela escola como uma alternativa para a formação integral dos jovens.

Palavras-chave Reforma do ensino médio, Flexibilização do ensino médio, Pedagogia da acumulação flexível 


\section{Introdução}

Em 2017, ainda no governo do presidente Michel Temer, o ensino médio sofreu profundas reformulações, com impacto significativo na educação profissional. Sem amplo debate com professores, entidades e comunidade científica de modo geral, em curto período de tempo o projeto de lei $n^{\circ}$ 6840/2014 (2013, na versão inicial, e dezembro de 2014, na versão substitutiva), as edições da Medida Provisória ${ }^{\circ} 746$ (setembro de 2016) e a nova Lei ${ }^{\circ} 13.415$ (fevereiro de 2017) culminaram na reforma do Ensino Médio, aprovada integralmente. $\mathrm{O}$ enfrentamento feito pelos setores progressistas da sociedade civil, em particular pelo Movimento Nacional em Defesa do Ensino Médio, e o movimento dos estudantes secundaristas, foi completamente desconsiderado.

Importante destacar que o debate ocorrido durante a tramitação desse processo que culminou na reforma do ensino médio pela promulgação da Lei 13.415/2017 expressou, mais uma vez, a contradição entre os interesses públicos e privados, que desta feita se materializaram na oposição entre rigidez e flexibilidade. Por um lado, as instituições que representam os setores privados que ampliaram os espaços na discussão das políticas públicas, com o apoio e a identidade conceitual dos dirigentes que integravam o Ministério da Educação (MEC) à época e do Conselho de Secretários de Educação (CONSED). A posição defendida por esses setores foi a flexibilização dos percursos formativos, de modo a permitir que o aluno, assegurada a base nacional comum, opte pelo aprofundamento em uma área acadêmica, ou pela formação técnica e profissional, a partir de sua trajetória e de seu projeto de vida. Para esse grupo, as Diretrizes Curriculares do Ensino Médio de 2012 - DCNEM/2012, são rígidas, uma vez que estabelecem um único percurso, disciplinar e com excessivo número de componentes curriculares, a partir do que propunham a flexibilização dos percursos.

De outro lado, as entidades e os intelectuais que historicamente têm buscado a construção de um projeto de educação que atendesse aos interesses da classe trabalhadora, mediante a organização de um currículo que integrasse, de forma orgânica e consistente, as dimensões da ciência, da tecnologia, da cultura e do trabalho, como modos de atribuir significado ao conhecimento escolar, exatamente como propunham as DCNEM/2012 ${ }^{1}$.

Desnecessário dizer que a posição que prevaleceu foi a da flexibilização curricular, expressa em uma organização curricular que admite diferentes percursos; a partir de, no máximo, 1800 horas dedicadas à Base Nacional Comum Curricular, incluindo a parte diversificada, o jovem, para "atender seu projeto de vida", pode escolher uma entre as diferentes áreas: linguagens e suas tecnologias, matemática e suas tecnologias, ciências da natureza e suas tecnologias, ciências humanas e sociais aplicadas, e formação técnica e profissional.

A primeira consideração a fazer com relação à essa proposta de organização curricular é seu caráter de aligeiramento da formação; nesse sentido, flexibilização tem o sentido de superficialidade, de simplificação. Isso porque a carga horária destinada à formação geral fica reduzida a 1800 horas no máximo, com apenas dois componentes curriculares obrigatórios em todo o percurso: língua portuguesa e matemática; os demais componentes curriculares têm carga horária reduzida, contradizendo a proposta de educação integral, eixo das DCNEM/2012 ${ }^{1}$.

Outra dimensão a considerar é que flexibilização também passa a significar redução de custos; inicialmente porque a escolha de um itinerário leva à necessidade de menor número de docentes e pode ser uma forma de resolver, embora de modo equivocado, a crônica falta de docentes em algumas disciplinas, notadamente nas áreas de ciências exatas e ciências da natureza. Como cada sistema de ensino pode ofertar os itinerários formativos que considerar adequados segundo as possibilidades estruturais e de recursos das instituições ou redes de ensino, essa oferta pode se restringir a apenas um itinerário, dentre os menos complexos e, portanto, que consomem menos recursos humanos, materiais e financeiros; reside aí o caráter redutor de custos. Isso ocorre também pela determinação que a formação geral básica tem apenas definida sua duração máxima, e não mínima; assim, os sistemas de ensino têm autonomia para definir a duração dessa formação, que pode ser inferior a 1800 horas, afastando-se ainda mais da possibilidade de uma educação integral.

Por outro lado, essa perspectiva de redução de custos é contraditada pela proposta de expansão da duração do ensino médio, que deve alcançar, progressivamente, 1400 horas/ano, ou seja, 07 horas/dia, para constituir-se em escolas de período integral; em cinco anos, a partir de 2017, as escolas de ensino médio devem atingir 1000 horas em 200 dias letivos, o que implica em 5 horas diárias de atividades. As escolas que passarem a ofertar o ensino integral a partir da 
vigência da Lei e a atender aos critérios estabelecidos pelo MEC, terão apoio financeiro por dez anos, mediante formalização de termo de compromisso que explicite as ações a serem realizadas $\mathrm{e}$ as metas a serem atingidas. Esse repasse, calculado pelo número de matrículas cadastradas, embora obrigatório, dependerá da disponibilidade orçamentária do MEC. As escolas que estiverem localizadas nas regiões com menores índices de desenvolvimento humano (IDH) e tiverem resultados mais baixos nos processos nacionais de avaliação do ensino médio, terão prioridade no apoio financeiro. A possibilidade desse financiamento, contudo, fica afastada pelos sucessivos cortes no orçamento destinado à educação, notadamente no governo do Presidente Jair Bolsonaro, e pela crise orçamentário-financeira porque passam as unidades federadas, as grandes responsáveis pela oferta de Ensino Médio, o que leva a concluir que predomina a lógica de uma organização curricular redutora de custos. Assim, a organização curricular determinada pela Lei obedece ao princípio da flexibilidade, com redução de custos, o que contradiz a pretensa expansão da duração, visando a implantação de escolas médias de educação integral.

Ainda na perspectiva de aligeiramento com redução de custos, a flexibilização, na educação técnica e profissional, em uma manifesta retomada do Decreto no 2.208/97, determina que o currículo poderá ser organizado em módulos com sistema de créditos e terminalidade específica; essa flexibilização abre a possibilidade, reincorporada pela Lei 13.415/2017, de que sejam firmados convênios com instituições de ensino reconhecidas, que ofertem formação técnica $\mathrm{e}$ profissional de modo presencial e a distância, de modo que as competências e os cursos desenvolvidos em outros espaços sejam validados.

No caso específico das competências, elas poderão ser certificadas desde que comprovadas por demonstração prática, experiências de trabalho supervisionadas ou adquiridas fora do ambiente escolar, o que permite reconhecer conhecimentos tácitos. As novas normas para a educação técnica e profissional, portanto, atendem amplamente ao princípio da flexibilização, o que, nesse caso, implica em desconstrução da proposta curricular da escola.

A flexibilização proposta pela Lei também atinge os docentes, em especial os da educação técnica e profissional, que poderão ministrar conteúdos de áreas afins à sua formação ou experiência profissional desde que atestado seu notório saber por titulação específica ou práti- ca de ensino em unidades educacionais da rede pública, privada ou em corporações. Ou seja, a flexibilização também significa desprofissionalização, perspectiva institucionalizada pelas leis 13.429/2017 e 13467/2017, que regulamentam, respectivamente, a terceirização dos serviços e as relações de trabalho (nova Consolidação das Leis Trabalhistas-CLT).

\section{Tendências e desafios}

\section{A reforma do ensino médio, ao desqualificar esse nível de ensino em nome da flexibilização, reforça a tese da dualidade invertida}

A par do caráter desqualificador da reforma do ensino médio, a análise dos dados sobre acesso e sucesso à educação nos últimos anos vêm mostrando uma queda progressiva nos indicadores educacionais, que revelam a redução das oportunidades educacionais, principalmente para os segmentos vulneráveis das juventudes, e para os jovens das famílias que vivem do trabalho. A par dessa redução, em sentido contrário, mas a ela dialeticamente relacionado, o crescimento do número de jovens que não trabalham e também dos que nem estudam nem trabalham.

Segundo os dados da PNAD de $2017^{2}$, o número de pessoas entre 15 e 29 anos que não trabalham, não estudam e não se qualificam profissionalmente, cresceu 5,9\% de 2016 para 2017, o que equivale a mais de 619 mil pessoas. Em 2016 eram 10,5 milhões, número que cresceu para 11,2 milhões em 2017, de um contingente de 48,5 milhões de pessoas nessa faixa etária.

Desdobrando os dados por sexo, cor ou raça, verifica-se que os maiores percentuais estão entre as mulheres, $28,7 \%$ contra $17,4 \%$ dos homens, e entre os de cor preta ou parda, $25,9 \%$ contra $18,7 \%$ de brancos.

Em consequência, estudos da $\mathrm{OCDE}^{3}$ apontam o Brasil como um dos países com o maior número de pessoas sem diploma de ensino médio; mais da metade dos adultos (52\%) com idade entre 25 e 64 anos não atingiram esse nível de formação.

Entre os jovens em idade escolar, embora a taxa de escolarização seja de $87,2 \%$, a taxa ajustada de frequência escolar líquida foi de $68,4 \%$, indicando quase 2 milhões de estudantes atrasados e 1,3 milhão fora da escola; os dados mostram que é no ensino médio que estão as taxas mais altas de atraso e evasão, indicando que os jovens 
se distanciam das possibilidades de acesso à educação, enquanto direito fundamental.

Essa tendência se reforça com a redução, em 2017, de 1,3 milhões de matrículas na educação básica em comparação com o ano de $2014(2,6)$ e a taxa de distorção idade-série alcança $24,7 \%$ das matrículas dos anos finais do ensino fundamental e $28,2 \%$ das matrículas do ensino médio.

Segundo o mesmo relatório, a proporção de alunos do sexo masculino com defasagem de idade em relação à etapa que cursam é maior do que a do sexo feminino em todas as etapas de ensino. Com relação à cor/raça, percebe-se que as maiores proporções de alunos de cor/raça branca são identificadas na creche $(54,7 \%)$ e na educação profissional concomitante ou subsequente $(50,1 \%)$, representando mais da metade dos alunos dessas etapas; pretos e pardos são maioria nas demais etapas de ensino, em especial na educação de jovens e adultos (EJA), onde representam $72,3 \%$ dos alunos. Esses percentuais podem ser maiores, uma vez que a ausência da informação de cor/raça ainda alcança $23,0 \%$ em cada uma das etapas da educação básica.

Especificamente no ensino médio, em 2018, foram registradas 7,7 milhões de matrículas, seguindo a tendência de queda nos últimos anos; nesse período, o número total de matrículas no ensino médio reduziu $7,1 \%$. No sentido contrário, a matrícula integrada à educação profissional cresceu $24,9 \%$ no último ano, passando de 468.212, em 2014, para 584.564 matrículas, em $2018^{4}$.

Com relação à localização, o número de matrículas do ensino médio concentra-se $(95,3 \%)$ em escolas urbanas. Além disso, 96,1\% das matrículas da zona rural são atendidas pela rede pública. A rede federal é a que apresenta, proporcionalmente, o maior número de matrículas localizadas na zona rural.

Os números aqui apresentados permitem algumas conclusões acerca da ampliação dos direitos à educação da classe trabalhadora. Inicialmente, há que considerar que a oferta de Ensino Médio, integrado ou não à EP, nível mais crítico com relação à inclusão, é predominantemente para os jovens brancos, masculinos e urbanos.

Em seguida, estudos têm mostrado que a taxa de desocupação dos jovens mais pobres que têm entre 11 a 14 anos de estudos, o que corresponderia ao ensino médio, pelo menos incompleto, não se reduziu com a ampliação da escolaridade; ao contrário, se elevou, mostrando que o esforço educacional deste segmento não diminui suas dificuldades de obtenção de ocupação. São os jovens pobres, mesmo escolarizados, os que têm mais dificuldade de acesso a trabalho ${ }^{5}$.

A hipótese com a qual venho trabalhando nos últimos anos, provocada pelas pesquisas de $\mathrm{Zibas}^{6}$ e por minhas próprias investigações ${ }^{7}$, é a da inversão da proposta dual que, até os primeiros anos da década de 1990, apresentava a escola média de educação geral para a burguesia e a escola profissional para os trabalhadores. E, dadas as condições de precarização que as escolas médias públicas que atendem os que vivem do trabalho têm apresentado, a educação geral, antes reservada à elite, quando disponibilizada aos trabalhadores, banalizouse e desqualificou-se. Ou seja, a burguesia, quando disponibiliza a versão geral para os trabalhadores, o faz de forma desqualificada; e o ensino médio de educação geral passou a ser escola para os filhos dos outros, enquanto a educação em ciência e tecnologia passou a ser a opção dos filhos da burguesia, mesmo que no ensino superior; para esses, o ensino médio é apenas um degrau necessário para o acesso aos cursos valorizados pelo mercado, no regime de acumulação flexível ${ }^{8}$.

Os dados apresentados até aqui, portanto, mostram que a perspectiva é a redução dos indicadores de acesso e sucesso no ensino médio para a classe trabalhadora, a par da redução das oportunidades de emprego, por muitos justificada pela falta de escolaridade e pela baixa qualidade da escola pública. Como afirma a OCDE, $o$ menor nivel de escolaridade tende a ser associado com a maior desigualdade de renda; menos emprego e salários mais baixos ${ }^{3}$.

\section{A flexibilização da proposta curricular do ensino médio é a expressão pedagógica da flexibilização do regime de acumulação}

Como já tenho afirmado em outros artigos ${ }^{9}$, a flexibilização do Ensino Médio é uma das expressões do projeto pedagógico do regime de acumulação flexível, cuja lógica continua sendo a distribuição desigual do conhecimento, porém com uma forma diferenciada. Esse regime se fundamenta, entre outras características, na flexibilidade dos processos de trabalho, dos mercados de trabalho, dos produtos e padrões de consumo. Essa flexibilização vem acompanhada pela combinação entre integração produtiva, investimento em tecnologia intensiva de capital e de gestão e consumo precarizado da força de trabalho, acentuando o desenvolvimento desigual, tanto entre setores como entre regiões geográficas.

Como esse processo, por natureza é precarizador e intensificador do trabalho, para que o 
capital possa confirmar-se enquanto princípio abrangente de síntese, os trabalhadores também devem passar por um processo de redução ontológica. Assim é com tudo o que não possa ser completamente abrangido pela lógica capitalista: primeiro precisa ser excluído, em seguida reduzido à dimensão meramente econômica para, depois, ser incluído sob outro estatuto ontológico, processo que se dá, não individualmente, mas no bojo das relações sociais e produtivas, ao longo da história ${ }^{9}$.

$\mathrm{Ou}$, como afirma Harvey ${ }^{10}$, a condição de existência de um regime de acumulação é a correspondência entre a transformação das condições de produção e de reprodução dos assalariados, de modo a fazer com que os comportamentos de todos os tipos de agentes político-econômicos mantenham o sistema funcionando; ou seja, a correspondência entre as formas de disciplinamento e as necessidades do sistema produtivo, relativas à formação de trabalhadores e dirigentes.

O regime de acumulação flexível, portanto, demanda a formação de novas formas de subjetividade, flexíveis, para o que, na concepção gramsciana, se constitui uma nova pedagogia a partir das mudanças estruturais; essa nova pedagogia objetiva novas formas de disciplinamento, principalmente da força de trabalho, sobre a qual recaem os resultados do acelerado processo de destruição e reconstrução de habilidades, os níveis crescentes de desemprego estrutural, a redução dos salários e a desmobilização sindical ${ }^{10}$.

Essa pedagogia responde ao processo que chamei, em outro texto, de inclusão excludente: do ponto de vista do mercado, ocorre um processo de exclusão da força de trabalho dos postos reestruturados, para incluí-la de forma precarizada em outros pontos da cadeia produtiva. Já do ponto de vista da educação, se estabelece um movimento contrário, dialeticamente integrado ao primeiro: por força de políticas públicas "professadas" na direção da democratização, aumenta a inclusão em todos os pontos da cadeia, mas precarizam-se os processos educativos, que resultam em mera oportunidade de certificação, os quais não asseguram nem inclusão nem permanência ${ }^{11}$.

Assim é que o discurso da acumulação flexível sobre a educação aponta para a necessidade da formação de profissionais flexíveis, que acompanhem as mudanças tecnológicas decorrentes da dinamicidade da produção científico-tecnológica contemporânea, ao invés de profissionais rígidos, que repetem procedimentos memorizados ou recriados por meio da experiência. Para que esta formação flexível seja possível, propõe a substi- tuição da formação especializada, adquirida em cursos de educação profissional e tecnológica, por uma formação mais geral.

No caso específico do atual Ensino Médio, a formação geral, dada a duração de apenas 1800 horas a ser complementada pelos estudos em uma área específica ou por educação técnica e profissional aligeirada, em princípio responderia a essa preparação para o mundo flexibilizado, porque a formação aprofundada ou mesmo especializada, por ser considerada rígida, não se justificaria pela suposta obsolescência do conhecimento. Assim, uma base geral seria suficiente para assegurar a flexibilidade na relação com o conhecimento, acompanhada pelo desenvolvimento das competências cognitivas básicas, uma vez que aprender ao longo da vida é uma categoria central na pedagogia da acumulação flexível. Se o trabalhador transitará, ao longo de sua trajetória laboral, por inúmeras ocupações e oportunidades de educação no trabalho, não há razão para investir em formação básica ou profissional especializada, como já propunha o Banco Mundial como política para os países pobres desde a década de noventa ${ }^{12}$; na perspectiva da pedagogia da acumulação flexível, a integração entre teoria e prática se dará ao longo das trajetórias de trabalho, secundarizando-se a formação escolar, tanto de caráter geral como profissional. Justifica-se, dessa forma, propostas aligeiradas de formação.

O que o discurso da pedagogia da acumulação flexível não revela é que, ao destruírem-se os vínculos entre qualificação e trabalho pela utilização das novas tecnologias, banaliza as competências, tornando-as bastante parecidas e com uma base comum de conhecimentos de automação industrial, a par da estratégia toyotista de definir a produção pela demanda, quando o mercado de trabalho passa a reger-se pela lógica dos arranjos flexíveis de competências diferenciadas ${ }^{7}$.

Diferentemente do que ocorria no taylorismo/fordismo, onde as competências eram desenvolvidas com foco em ocupações previamente definidas e relativamente estáveis, a integração produtiva se alimenta do consumo flexível de competências diferenciadas, que se articulam ao longo das cadeias produtivas. Estas combinações não seguem modelos pré-estabelecidos, sendo definidas e redefinidas segundo as estratégias de contratação e subcontratação que são mobilizadas para atender à produção puxada pela demanda do mercado. São combinações que ora incluem, ora excluem trabalhadores com diferentes qualificações, de modo a constituir corpos coletivos de trabalho dinâmicos, por meio de uma 
rede que integra diferentes formas de subcontratação e trabalho temporário e que, ao combinar diferentes estratégias de extração de mais-valia, asseguram a realização da lógica mercantil.

Se há combinação entre trabalhos desiguais e diferenciados ao longo das cadeias produtivas, há também demandas diferenciadas, e desiguais, de qualificação dos trabalhadores, que podem ser rapidamente atendidas pelas estratégias da aprendizagem flexível, o que permite que as contratações sejam definidas a partir de um perfil de trabalhador com aportes de educação geral e capacidade para aprender novos processos, e não a partir da qualificação ${ }^{7}$.

Daí o caráter "flexível" da força de trabalho; importa menos a qualificação prévia do que a adaptabilidade, que inclui tanto as competências anteriormente desenvolvidas, cognitivas, práticas ou comportamentais, quanto a competência para aprender e para submeter-se ao novo, o que supõe subjetividades disciplinadas que lidem adequadamente com a dinamicidade, com a instabilidade, com a fluidez.

O discurso da necessidade de elevação dos níveis de conhecimento e da capacidade de trabalhar intelectualmente, quando adequadamente analisado a partir da lógica da acumulação flexível, mostra seu caráter concreto: a necessidade de ter disponível para consumo, nas cadeias produtivas, força de trabalho com qualificações desiguais e diferenciadas que, combinadas em células, equipes, ou mesmo linhas, atendendo a diferentes formas de contratação, subcontratação e outros acordos precários, assegurem os níveis desejados de produtividade, por meio de processos de extração de mais-valia que combinam as dimensões relativa e absoluta.

Esta forma de consumo da força de trabalho ao longo das cadeias produtivas aprofunda a distribuição desigual do conhecimento, onde, para alguns, dependendo de onde e por quanto tempo estejam integrados nas cadeias produtivas, se reserva o direito de exercer o trabalho intelectual integrado às atividades práticas, a partir de extensa e qualificada trajetória de escolarização; o mesmo não ocorre com a maioria dos trabalhadores, que desenvolvem conhecimentos tácitos pouco sofisticados, em atividades laborais de natureza simples e desqualificada e são precariamente qualificados por processos rápidos de treinamento, com apoio nas novas tecnologias e com os princípios da aprendizagem flexível.

Nesse contexto de distribuição desigual, se insere o novo Ensino Médio; diferentemente da proposta que integrava as DCEM/2012 $2^{1}$, a or- ganização curricular aprovada, ao flexibilizar os percursos, institucionaliza o acesso desigual e diferenciado ao conhecimento.

Em resumo, o Ensino Médio, na atual versão, integrando a pedagogia da acumulação flexível, tem como finalidade a formação de trabalhadores com subjetividades flexíveis, por meio de uma base de educação geral complementada por itinerários formativos por área de conhecimento, incluindo a educação técnica e profissional; a formação profissional é disponibilizada de forma diferenciada por origem de classe, de modo a levar os que vivem do trabalho a exercer, e aceitar, de forma natural, as múltiplas tarefas no mercado flexibilizado. Ser multitarefa, neste caso, implica exercer trabalhos disponibilizados pelo mercado, para os quais seja suficiente um rápido treinamento, a partir de algum aporte de educação geral, seja no nível básico, técnico ou superior.

Para alguns, significará exercer trabalhos qualificados e criativos; esses não serão atingidos pela reforma do Ensino Médio porque dispõem, em face de sua origem de classe, de outros espaços e itinerários de formação, que não o ensino médio em escola pública. Para a maioria dos trabalhadores, contudo, ser multitarefa significará exercer trabalhos temporários simplificados, repetitivos e fragmentados, que não necessitam de formação qualificada, mas talvez de certificados ou reconhecimento de competências, o que o atual Ensino Médio talvez atenda.

A análise levada a efeito vai ao encontro dos dados apresentados no item 2.1; a tendência decrescente da matrícula no nível médio aliada ao fato de que as taxas de abandono e insucesso atingem predominante os filhos dos estratos mais baixos da classe trabalhadora e negros e pardos, reforçam o caráter excludente do Ensino Médio, que disponibiliza para o mundo do trabalho um grande contingente de trabalhadores desqualificados, que terão como alternativa trabalhos precarizados. Fecha-se o ciclo da exclusão includente na ponta da escola, mostrando a reforma do ensino médio seu caráter reprodutor no regime de acumulação flexível.

\section{A organização curricular flexível completa o quadro da formação precarizada}

A flexibilização da organização curricular e da metodologia é uma das formas de atender à finalidade de formação de profissionais, cuja força de trabalho poderá ser consumida de forma mais ou menos predatória, ao longo das cadeias produtivas. 
Sua concepção se insere no contexto da chamada aprendizagem flexível, entendida como flexibilização dos itinerários, dos tempos e dos espaços de aprendizagem, tal como propõe a reforma do Ensino médio; neste caso, a justificativa é autonomia do aluno, em contraposição à rigidez dos tempos dos cursos tradicionais.

Como reza o parágrafo 9 do art. 17 da Res. $03 / 2018$, que atualiza as DCNEM de $2012^{1}$, a organização curricular do ensino médio deve oferecer tempos e espaços próprios ou em parcerias com outras organizações para estudos e atividades, a fim de melhor responder à heterogeneidade e pluralidade de condições, múltiplos interesses e aspirações dos estudantes, com suas especificidades etárias, sociais e culturais, bem como sua fase de desenvolvimento $^{1}$.

Do ponto de vista epistemológico, a aprendizagem flexível pauta-se por fundamentos que diferenciam a nova proposta dos pressupostos teórico-metodológicos afirmados pelas DCNEM/2012; nesse documento, entre os conceitos centrais destacam-se práxis e totalidade, a partir da concepção materialista histórica que orientou sua elaboração ${ }^{1}$. A práxis é compreendida como atividade teórica e prática que transforma a natureza e a sociedade; prática, na medida em que a teoria, como guia da ação, orienta a atividade humana; teórica, na medida em que esta ação é consciente ${ }^{13}$.

Nessa concepção, a articulação entre teoria e prática é pressuposto epistemológico; partindo da compreensão que o processo de produção do conhecimento resulta da re-criação, ou seja, da reprodução da realidade no pensamento, o que ocorre por meio da atividade humana, processo através do qual a realidade adquire significado para os seres humanos, trabalho intelectual e atividade prática constituem uma dualidade dialética. Assim, se a prática não fala por si mesma, tendo que os fatos ou fenômenos serem identificados, analisados, interpretados, já que a realidade não se deixa revelar através da observação imediata, o trabalho intelectual passa a ser imprescindível no ato de conhecer. É no movimento do pensamento que se debruça sobre a realidade a ser conhecida, relacionando-se com a dimensão empírica na prática, que são construídos os significados; é pelo trabalho intelectual que a aparência dos fenômenos é superada, e as relações, as conexões, as estruturas internas, as formas de organização, as relações entre parte e totalidade, as finalidades, passam a ser conhecidas; como resultado desse processo, podem transformar-se as consciências, as relações sociais e a própria socie- dade, desde que as condições materiais necessárias estejam dadas. Esse processo de construção de consciências intelectualmente e eticamente autônomas, visando a construção de uma sociedade mais justa, constitui-se em um dos mais caros objetivos da Educação Básica e, portanto, do Ensino Médio.

Ao contrário, a organização curricular flexível, centrada nos indivíduos e pautada por seus projetos de vida, busca superar a concepção curricular proposta pelas DCNEM/2012, onde a amplitude, a profundidade e a dimensão práxica com que seriam tratados os conteúdos visando a formação integral, passam a ser substituídas por uma trajetória em que a formação geral fica reduzida e os itinerários conduzem, para além da escolha precoce, à fragmentação na relação com o conhecimento. Seus fundamentos não são mais os das teorias modernas, nem mais contemplam a concepção de totalidade; ao contrário, inscrevem-se no âmbito das teorias pós-modernas que sustentam a concepção de aprendizagem flexível. A produção de conhecimentos deixa de ser compreendida como resultante da relação entre teoria e prática para resultar dos discursos intersubjetivos, nesse caso, da interlocução dos alunos nas redes, nas comunidades de prática, mediada pelas tecnologias.

Do ponto de vista dessas teorias, o conhecimento é uma impossibilidade histórica, uma vez que ao pensamento humano é impossível apreender a realidade, porque está demarcado por diversidades culturais; assim, as interpretações são diversas, sendo verdadeiras apenas no contexto cultural que lhes deu origem. O que há são interpretações, narrativas atreladas à prática cotidiana, reduzindo-se o conhecimento à linguagem, do que decorre que a teoria se constrói mediante o embate de discursos intersubjetivos, ao nível da superestrutura; ou seja, pelo confronto de discursos, e não pelo confronto entre pensamento e materialidade.

Assim, não há verdade, não há possibilidade de conhecer, o que resulta no ceticismo epistemológico $^{14}$. Importante destacar que não há negação da realidade e sim da possibilidade de apreendê-la, pois não há discursos desinteressados, uma vez que são produzidos a partir de uma dada cultura e manifestam relações de poder.

Tem-se, como resultado, a superficialização do processo educativo, reduzindo-se o conhecimento a narrativas sobre as atividades cotidianas, fenômeno denominado por Moraes $^{14}$, de recuo da teoria; essa precarização da formação atinge a formação docente, o que fecha o círculo da fragi- 
lização dos processos educativos sistematizados: acesso restrito à teoria por trabalho intelectual pouco complexo.

Por outro lado, a afirmação do conhecimento como resultante do confronto de discursos, ao não o reconhecer como resultante da relação entre teoria e prática, entre trabalho intelectual e atividade, põe por terra a concepção de práxis, $o$ que conduz a duas dimensões que caracterizam o pós-modernismo: o presentismo e o pragmatismo, que, não por coincidência, alimentam o consumo e, portanto, sustentam a lógica mercantil. Se não é possível conhecer a realidade, também não é possível transformá-la!

Com relação ao recuo da teoria, afirmouse em outro texto, que a Lei 13.415/2017 abre a possibilidade de substituir parte da formação que seria dada nas escolas de Ensino Médio por cursos a distância, módulos ou cursos ofertados por outras instituições, em um nítido processo de flexibilização curricular que relativiza a organização curricular sistematizada, notadamente na formação técnica e profissional. Nesse caso específico, o recuo à teoria é de tal monta que se admite a certificação de competências comprovadas por exercício profissional supervisionado, sempre lembrando que se está falando de um jovem adolescente, e não de um trabalhador adulto e experiente; certifica-se o conhecimento tácito7.

A negação da práxis enquanto possibilidade de transformação anula os projetos, as possibilidades, e a historicidade: o que vale é o presente. A experiência histórica é substituída pela experiência do momento; as organizações históricas e suas experiências acumuladas são substituídas pelo ativismo, onde a sensação do ineditismo nas ações voluntaristas torna-se a referência maior das escolhas das posturas e das posições políticas $^{15}$.

A História é compreendida como uma forma específica de discurso, a forma narrativa, que, segundo um roteiro previamente definido, atribui um efeito de verdade aos fatos e dados históricos, revestindo-os de uma racionalidade que não existe na realidade; portanto, a História não existe. Em consequência, também não existe o universalismo e nem o coletivo, pois os fenômenos sociais não podem ser explicados por referências externas a eles, uma vez que essas referências são atravessadas por leituras particularistas, diversas culturalmente.

Se não há história, não há valores, nem princípios ou fundamentos e não há futuro; só o presente, que deve ser vivido em sua completude. Reforça-se o individualismo, reduzindo-se a sociedade à interação entre indivíduos e as relações sociais são reduzidas ao plano individual, das escolhas pessoais. Consequentemente, não há teorias sociais, pois estas são ilusões que disfarçam interesses particulares; a totalidade passa a ser um recurso metodológico impossível, pois não há como estabelecer relações causais entre fenômenos sociais. A totalidade é substituída pela fragmentação.

A organização curricular proposta pela reforma do Ensino Médio, portanto, pela flexibilização que resulta na sua precarização epistemológica, integra-se perfeitamente ao regime de acumulação flexível, pelas novas formas de disciplinamento que fragilizam a relação com o conhecimento, reduzem a relação entre teoria e prática ao pragmatismo, matam a crença na possibilidade de construção de uma nova sociedade referendando o presentismo e substituem os processos coletivos na vida social e produtiva pelo individualismo.

\section{Perspectivas}

A análise levada a efeito nesse texto aponta o peso das dimensões materiais - no caso, o regime de acumulação flexível, na rearticulação das alianças que permitam o seu crescente desenvolvimento; constitui-se um novo bloco hegemônico que, inexoravelmente, e sem resistência efetiva, vai processando o ajuste a favor do capital: a reforma da previdência, o ajuste dos gastos públicos que penalizam a educação e a saúde, além de outros investimentos, a reforma da CLT, a aprovação do projeto de lei que regulamenta a terceirização indiscriminada, e, na área da educação, o ajuste no Ensino Médio.

Contudo, no bojo das contradições, abre-se uma pequena brecha no art. $7^{\circ}$. da Res.03/2018/ $\mathrm{CNE} / \mathrm{CEB}$, parágrafos $1^{\circ}$. e $2^{\circ}$, que permitem organizações curriculares alternativas pelas escolas, no exercício de sua autonomia:

$\$ 1^{\circ}$ Atendidos todos os direitos e objetivos de aprendizagem instituídos na Base Nacional Comum Curricular (BNCC), as instituições e redes de ensino podem adotar formas de organização e propostas de progressão que julgarem pertinentes ao seu contexto, no exercício de sua autonomia, na construção de suas propostas curriculares e de suas identidades.

$\$ 2^{\circ}$ O currículo deve contemplar tratamento metodológico que evidencie a contextualização, a diversificação e a transdisciplinaridade ou outras formas de interação e articulação entre diferentes 
campos de saberes específicos, contemplando vivências práticas e vinculando a educação escolar ao mundo do trabalho e à prática social e possibilitando o aproveitamento de estudos e o reconhecimento de saberes adquiridos nas experiências pessoais, sociais e do trabalho ${ }^{16}$.

A organização de projetos interdisciplinares e de outras formas de organização curricular que insiram o aluno na prática social usando os conhecimentos científicos e metodológicos para uma adequada leitura do real seguida pela prática coletiva de construção de entendimentos e de soluções, fundada na categoria práxis, pode ser uma alternativa para a formação integral de jovens que vislumbrem possibilidades de emancipação no bojo do movimento contra-hegemônico.
Contudo, não há como ignorar que a análise realizada mostra a dura realidade expressa pelo peso da materialidade e pela fragilização das clássicas instâncias superestruturais que historicamente se responsabilizaram pela formação no plano contra-hegemônico: escolas, partidos, sindicatos. E aponta para a necessidade de reconstruir os velhos e construir os novos espaços formativos e organizativos, em busca da superação do estado de perplexidade e quase paralisia que assola os movimentos contra-hegemônicos no momento histórico em que se vive, sob o governo de Jair Bolsonaro. Sob pena de manter anestesiada a resistência e abrir mão das possibilidades de transformação! 


\section{Referências}

1. Brasil. Conselho Nacional de Educação. Resolução nº 2, de 30 de janeiro de 2012. Dispõe sobre as Diretrizes Curriculares Nacionais para o Ensino Médio. Diário Oficial da União 2012; 31 jan.

2. Instituto Brasileiro de Geografia e Estatística (IBGE). Pesquisa Nacional por Amostra de Domicílios - PNAD. Rio de Janeiro: IBGE; 2017.

3. Organização para a Cooperação e Desenvolvimento Econômico (OCDE). Um olhar sobre a educação. Paris: OCDE; 2018.

4. Instituto Nacional de Estudos e Pesquisas Educacionais Anísio Teixeira (INEP). Sinopse estatística da educação básica. Brasília: INEP; 2018.

5. Ribeiro R, Neder H. Juventude(s): desocupação, pobreza e escolaridade. Nova Econ 2009; 19(31):475-506.

6. Zibas DML. A reforma do Ensino Médio no Chile: vitrina para a América Latina? Cad Pesq 2002; 115:233262.

7. Kuenzer AZ. Da dualidade assumida à dualidade negada: o discurso da flexibilização justifica a inclusão excludente. Educ Soc 2007; 28:1153-1178.

8. Kuenzer AZ. O Ensino Médio no Plano Nacional de Educação 2011-2020. Educ Soc 2010; 112:851-874.

9. Kuenzer AZ. Trabalho e escola: a flexibilização do Ensino Médio no contexto da acumulação flexível. Educ Soc 2017; 38:331-354.

10. Harvey D. Condição pós-moderna. São Paulo: Loyola; 1992.

11. Kuenzer AZ. Exclusão includente e inclusão excludente: a nova forma de dualidade estrutural que objetiva as novas formas de relação entre educação e trabalho. In: Saviani D, Sanfelice JL, Lombardi JC. Capitalismo, Trabalho e Educação. 2a ed. Campinas: Autores Associados; 2005. p. 77-96.

12. Kuenzer AZ. O ensino Médio no Contexto das Políticas Públicas de Educação no Brasil. Revista Brasileira de Educação 1997; 4:2077.

13. Vázquez AS. Filosofia da praxis. Rio de Janeiro: Paz e Terra; 1968.

14. Moraes MCMM, organizador. Iluminismo às Avessas: produção de conhecimento e políticas de formação docente. Rio de Janeiro: DP\&A; 2003

15. Debord G. A sociedade do espetáculo. São Paulo: eBooksBrasil; 2013.

16. Brasil. Conselho Nacional de Educação. Resolução no 3, de 8 de novembro de 2018. Atualiza as Diretrizes Curriculares Nacionais para o Ensino Médio. Diário Oficial da União 2018; 22 nov.

Artigo apresentado em 30/04/2019

Aprovado em 20/08/2019

Versão final apresentada em 03/10/2019 